\section{Surfactant administration in premature infants with RDS}

\author{
ISMETA KALKAN • SUADA HELJIĆ • AMRA ČENGIĆ • VERICA MIŠANOVIĆ • \\ DUŠKO ANIĆ • FEDŽAT JONUZI • HAJRIJA MAKSIĆ
}

\author{
ISMETA KALKAN $(\bowtie) \cdot$ SUADA HELJIĆ • \\ AMRA ČENGIĆ • VERICA MIŠANOVIĆ • \\ DUŠKO ANIĆ • FEDŽAT JONUZI • \\ HAJRIJA MAKSIĆ \\ Neonatal Intensive Care Unit \\ Pediatric Hospital \\ Clinical Centre Sarajevo \\ Bolnička 25 \\ 71000 Sarajevo \\ Phone:++38733297716 \\ e-mail:vrabac7@yahoo.com
}

\begin{abstract}
Background. The significant advancement in the treatment of respiratory distress syndrome can be attributed to prenatal identification of high risk pregnancies, prevention of illness through antenatal care, prenatal administration of glucocorticoids, advancement in respiratory support and surfactant therapy. These measures resulted in the reduction of mortality and morbidity rates in preterm infants.

Patients and methods. We analyzed data of 78 preterm babies with respiratory distress syndrome hospitalized in the NICU of the Pediatric Clinic, KCU Sarajevo. All children included in the study were mechanically ventilated and treated with one or more doses of bovine surfactant (Survanta) as rescue therapy. Surfactant was given to children with clinical and radiological signs of RDS, who required $\mathrm{FiO}_{2}>0,40$. We used the standard procedure of giving surfactant therapy to intubated children in sterile conditions, after we confirmed, by X-ray, correct tube placement.

Results. We investigated the clinical efficacy of surfactant in relation to time of administration, $\mathrm{O}_{2}$ requirement and necessity of one or more doses of surfactant. We found that early treatment with surfactant replacement- within 6 hours of birth-is more effective, and resulted in a significant reduction of mortality rate $(p<0,01)$. Treatment with multiple doses is more effective in comparison to one dose, although there was not a significant difference $(p<0,20)$ between the treated groups. There is a significant difference $(p<0,01)$ between groups related to $\mathrm{O}_{2}$ requirement. In the group of babies which required $60 \%$ or more $\mathrm{O}_{2}$ concentration in inhaled air at the time of surfactant replacement, mortality rate was significantly higher $(p<0,01)$.

Conclusion. Our study confirmed the benefits of surfactant therapy in preterm babies with respiratory distress syndrome. We confirmed the advantages of early treatment vs. late treatment, but we could not confirm the obvious advantage of multiple over single doses. So, a reasonable recommendation is to treat the infants as soon as clinical signs of developing respiratory distress appear with an individual dose for each infant.
\end{abstract}

Key words: respiratory distress syndrome, surfactant, preterm

\section{Introduction}

Respiratory distress syndrome, (RDS, hyaline membrane disease, hyposurfactosis) is the most common disturbance in preterm infants, appearing in approximately $60 \%$ of infants born before 30 weeks gestation. The main cause of the disease is inadequate amounts of lung surfactant. Surfactant replacement reduces mortality and morbidity rates in premature infants, reduces duration of ventilatory support, number of complications and medical costs. Surfactant therapy is not a substitute for an attempt to increase lung maturity by delaying premature delivery or by using antenatal corticosteroids with the aim of preventing RDS (1-5). Many studies of different regimes of surfactant therapy, related to time of application, have been undertaken during the 80 s and 90 s $(6,7,8)$.

Prophylactic surfactant replacement is given to preterm neonates at high risk of developing acute RDS in the delivery room, shortly after resuscitation, as they start to breathe. Rescue therapy refers to treatment given after the diagnosis is established, 2 to 24 hours after birth (3,9-11). Most centers use res- 
cue therapy as the mode of treatment. Each regime increases oxygenation of ventilated preterm babies and reduces mortality and morbidity rates. This correlates with a significant reduction of medical costs $(12,13,14)$.

The aim of this study was to find an optimal regime of surfactant therapy, early vs. late treatment, and also to test the efficacy of multiple doses vs. a single dose.

\section{Patients and methods}

The investigation included 78 preterm infants with RDS, between 25 and 35 weeks gestation, treated with surfactant. All children were hospitalized in the neonatal intensiv care unit (NICU) of the Pediatric Clinic, Clinical Centre Sarajevo during 2004 and 2005.

Surfactant was given to infants with radiological and clinical signs of RDS (tachypnea, cyanosis on room air) who required more then $40 \% \mathrm{O}_{2}$ in inhaled air. Surfactant was given after intubation, radiological confirmation of correct tube placement and stabilization of vital functions. We used bovine surfactant - Survanta, $4 \mathrm{ml} / \mathrm{kg}$, which was administered according to standard procedures. The following parameters were chosen on the ventilator: PIP (Positive Inspiratory Pressure) needed for the rising of the chest but without overdistension; pressure at the end of expiration (PEEP) of 4 $\mathrm{cm} \mathrm{H}_{2} \mathrm{O}$; inspiratory time (IT) of $0,5 \mathrm{sec}$., frequency of 30/min, start $\mathrm{FiO}_{2}$ 1,0. Surfactant was given in one or more doses, in sterile conditions. The second dose was given 12 hours after the first dose. Each dose was administered over 30s into each lung quadrant. If saturation fell below $85 \%$ we stopped with the instillation. Treatment was continued after $\mathrm{O}_{2}$ saturation improved upon previous values. Effects of surfactant therapy were assessed based on $\mathrm{O}_{2}$ saturation (determinated by pulse oximetry), gas analyses in arterial and capillary blood, the clinical condition of the child and chest X-ray.

The group of investigated children was divided into subgroups, depending on the number of doses received, time of treatment (early, late) and $\mathrm{O}_{2}$ requirement. Early treatment was related to

patients who received the first dose within 6 hours of birth and late treatment - six or more hours after birth. In regard to $\mathrm{O}_{2}$ requirements, our study group was divided into those who needed $<$ $60 \% \mathrm{O}_{2}$ in inhaled air and those who needed $60 \% \mathrm{O}_{2}$ or more.

\section{Results}

Comparing the results of early treatment (giving Surfactant within 6 hours of birth) and late treatment (six or more hours after birth) we found that there is a significant difference between treated groups $(p=0,005)$. In the study group which received surfactant within 6 hours of birth, 34 (out of 43) children survived, compared with 17 (out of 35) children who received surfactant 6 hours after birth or later (table 1).

\section{Table1.}

Outcome of illness in relation to time of first surfactant dose

\begin{tabular}{|c|c|c|c|c|c|}
\hline \multirow{2}{*}{ Hours } & Survived & Died & \multirow{2}{*}{ Total (\%) } & \multirow{2}{*}{$\chi^{2}$} & \multirow{2}{*}{$p$} \\
\hline & No (\%) & No (\%) & & & \\
\hline $0-6$ & $34(79)$ & $9(21)$ & $43(100)$ & \multirow{3}{*}{7,9} & \multirow{3}{*}{0,005} \\
\hline More then 6 & $17(49)$ & $18(51)$ & 35 (100) & & \\
\hline Total & 51 & 27 & 78 (100) & & \\
\hline
\end{tabular}

From the table 2, it can be seen that 53 (out of 78) children received one dose of surfactant comparable with 25 who received two doses. 38 (out of 53) children, who received one dose survived, whereas, only 13 (out of 25) children who received two doses survived. There is no significant difference between these two groups ( $p=0,088)$, although the mortality rate in children who received two doses of surfactant was lower in comparison with the group which received one dose.

There is a significant difference $(p=$ $0,015)$ between groups related to $\mathrm{O}_{2}$ requirement. In the group of children

\section{Table 2.}

\section{Outcome of illness in relation to number of doses}

\begin{tabular}{l|l|l|l|l|c}
\hline \multirow{2}{*}{$\begin{array}{l}\text { Number of } \\
\text { doses }\end{array}$} & Survived & Died & \multirow{2}{*}{ Total (\%) } & \multirow{2}{*}{$\chi^{2}$} & p \\
\cline { 2 - 4 } & No (\%) & No (\%) & & \\
\hline 1 dose & $38(72)$ & $15(28)$ & $53(100)$ & & \multirow{2}{*}{2,9} \\
\hline 2 doses & $13(52)$ & $12(48)$ & $25(100)$ & 0,088 \\
\hline Total & 51 & 27 & $78(100)$ & & \\
\hline
\end{tabular}

requiring $\mathrm{O}_{2}$ concentration less then $60 \%(n=22)$, as many as 19 (out of 22) survived in comparison with the group who required $60 \%$ or more oxygen, at the time of surfactant replacement, where 32 (out of 56 ) children survived (table 3). Early treatment with surfactant at lower $\mathrm{O}_{2}$ concentrations is associated with a lower mortality rate.

\section{Discussion}

Many clinical trials, carried out during the 80s and 90s, showed that surfactant use in preterm infants significantly reduces mortality rate and complications within 28 days of birth $(9,12)$. Our study, conducted on 78 preterm babies, showed that the overall percentage of survival in children treated with surfactant was $65,38 \%$. 24 hours after birth, as rescue therapy, when diagnosis of severe respiratory distress syndrome is established. On the other hand, treatment in the delivery room is considered optimal, only if it's given after establishing breathing and ventilation by positive pressure. In most of the studies, treatment of RDS with surfactant started between 2-4 hours after birth or in the delivery room after stabilization of the baby, within 15 minutes of birth. In relation to timing of the first dose, two strategies are used $(7,15,16)$.

In our study, the first dose of surfactant was given as soon as diagnosis of 
Table 3.

Outcome of illness dependent upon $\mathrm{O}_{2}$ requirement

\begin{tabular}{|c|c|c|c|c|c|}
\hline \multirow{2}{*}{$\begin{array}{l}\mathrm{O}_{2} \text { concen- } \\
\text { tration }\end{array}$} & Survived & Died & \multirow{2}{*}{ Total (\%) } & \multirow{2}{*}{$\chi^{2}$} & \multirow{2}{*}{$\mathrm{p}$} \\
\hline & No (\%) & No (\%) & & & \\
\hline$<0,6$ & $19(86)$ & $3(14)$ & $22(100)$ & \multirow{3}{*}{6,0} & \multirow{3}{*}{0,015} \\
\hline 0,6 or more & $32(57)$ & $24(43)$ & $56(100)$ & & \\
\hline Total & 51 & 27 & 78 (100) & & \\
\hline
\end{tabular}

severe respiratory distress syndrome was established: within 6 hours from birth (early treatment) and after 6 hours (late treatment). In the study group which received surfactant within 6 hours of birth, 34 (out of 43) children survived, compared with 17 (out of 35) children who received surfactant 6 hours after birth or later $(p<0,005)$. Our results confirm the advantages of early treatment vs. late treatment. So, a reasonable recommendation is to treat the infants as soon as clinical signs of developing respiratory distress appear. Waiting for the complete clinical picture to develop before commencing treatment will minimize the effect of surfactant therapy $(17,18)$. The treatment in the delivery room should be reserved for the smallest infants with the highest risk for developing acute RDS and should be given by a person experienced in neonatal resuscitation and surfactant administration (19).

In most cases, multiple doses of surfactant are being given, with the intent of avoiding functional inactivation of surfactant. Multiple doses are believed to be useful because the effect of one dose is considered transient $(10,20)$. When comparing multiple doses with single doses, authors $(7,9,21)$ have found a reduction in the frequency of pneumothorax and mortality rate (within 28 days) with multiple doses. It is not clear whether all sick infants benefit from multiple doses. Most children respond to treatment or re-treatment, but some of them show little or no response. These infants can have other illnesses like pneumonia, pulmonary hypoplasia or congenital heart disease. Structural immaturity of the lungs and birth asphyxia can reduce the response to surfactant therapy $(23,22)$.

In our study, there was no significant difference between groups treated with one and two or more doses $(p<0,088)$, although the mortality rate in children who received two doses of surfactant was lower compared with the group which received one dose. The necessity for more doses should be individualized and considered based on clinical circumstances, such as in infants with residual lung disease, so that the risk of complications like pneumothorax or prolonged ventilatory support can be avoided $(24,25)$.

It seems that early surfactant treatment, when $\mathrm{O}_{2}$ requirement is lower, reduces the need for later treatment, $\mathrm{O}_{2}$ requirement and mechanical ventilation. Surfactant given early is more effective. The optimal time for administration is not defined. The current recommendation is that a preterm baby with RDS needs surfactant replacement if he/she needs endotracheal intubation and if $\mathrm{O}_{2}$ requirement in inhaled air is more than $40 \%(26,27)$. In our study there is a significant difference $(p<0,05)$ between groups related to $\mathrm{O}_{2}$ requirement. In the group of children which required $\mathrm{O}_{2}$ concentrations less than $60 \%(n=22)$, as many as 19 (out of 22) survived compared with 32 (out of 56) who required $60 \%$ or more oxygen concentration in inhaled air at the time of surfactant replacement. Early treatment of surfactant with lower $\mathrm{O}_{2}$ requirements is associated with a lower mortality rate. Our study confirmed the benefits of surfactant use in preterm babies with respiratory distress syndrome. We confirmed the advantages of early treatment vs. late treatment, which is also connected with $\mathrm{O}_{2}$ requirement. In this study we could not confirm the advantage of multiple over single doses. Therefore a reasonable recommendation is to treat infants as soon as clinical signs of developing respiratory distress appear with individualized dosaging for each infant.

\section{REFERENCES}

1. Jobe AH. Lung Development. In: Martin RJ, Fanaroff AA, eds. Neonatal-perinatal Medicine, Diseases of the Fetus and Infant. St Louis: Mosby; 1997, pp 1019-1040.

2. Honrubia D, Stark AR. Respiratory Disorders. In: Cloherty JP, Eichenwald EC, Strak AR, eds. Manuale of Neonatal Care. Philadelphia: Lippincott, Williams\&Wilkins; 1997, pp 341-378.

3. Gomella TL, Gleason BL. Hyalin Membrane Disease. In: Gomella TL, eds. Neonatology. Appleton and Lange; 1988/89, pp 381-385.

4. Katz R. Function and Physiology of the Respiratory System. In: Furhman BP, Zimmerman JJ, eds. Pediatric critical care. St Louis: Mosby; 1992, pp 386-399.

5. Fackler JC, Arnold JH, Nickols DG, Rogers MC. Acute Respiratory Distress Syndrome. In: Rogers MC, eds. Textbook of Pediatric Intensive Care, Baltimore: Williams and Wilkins; 1996, pp 197-225.

6. Leahy A. Respiratory distress. In: Southall D, Coulter B, Ronald Ch, Nicholson S, Parke S, eds. International Child Health Care. London: BMJ; 2002, pp 129-131.

7. Jobe AH. Pulmonary surfactant therapy. New England Journal of Medicine 1993; 328:861-8. 
8. Enhoring G, Shennan A, Possmazer F. Prevention of neonatal respiratory distress syndrome by tracheal instillation of surfactant. Pediatrics 1985;76:145-53.

9. Schwartz RM, Luby AM, Scanlon JW, Kellogg RJ. Effect of surfactant on morbidity, mortality, and resource use in newborn infants weighting 500 to $1500 \mathrm{~g}$. New England Journal of Medicine 1944;330:1476-80.

10. Gortner LA. Multicenter randomized controlled trial of bovine surfactant for prevention of respiratory of distress syndrome. Lung 1990;168: 864-91.

11. Stevens TP, Blennov M, Soll RF. Early surfactant administration with brief ventilation vs. selective surfactant and continued mechanical ventilation for preterm infants with or at risk for RDS. Cochrane Database Syst Rev 2002;CD003063.

12. Jeffrey A, Timothy E. Hydrophobic Surfactant Proteins in Lung Function and Disease. New England Journal of Medicine 2002;347:21412148.

13. Soll RF, Blanco F. Natural surfactant extract versus synthetic surfactant for neonatal respiratory distress syndrome. Cochran Database Syst Rev 2001;CD000144.

14. Hafner D, Germann PG, Hauschke D. Comparison of rST-C surfactant with natural and synthetic surfactants after late treatment in a rat model of the acute respiratory distress syndrome. New England Journal of Medicine 1998;124(6):1083-90.

15. Soll RF. Appropriate surfactant usage in 1996. Eur J Pediatr 1996;2:S8-13.

16. Ehitelaw A. Controversies: synthetic or natural surfactant treatment for respiratory distress syndrome/The case for synthetic surfactant. J Perinatal Med 1996;24(5):427-35.

17. Gortner L.A. Multicenter randomized controlled trial of bovine surfactant for prevention of respiratory of distress syndrome. Lung 1990;168:864-91

18. Jobe A.H. Pulmonary surfactant therapy. New England Journal of Medicine 1993;328:861-8.

19. Speer CP, Halliday HL. Surfactant therapy in the newborn. Current Paediatrics 1994; 4:5-9.

20. Halliday HL. Where we are now with the prenatal steroids and postnatal surfactant. Biol Neonate 1996:69:186-7.

21. Mathay MA. The Acute Respiratory Distress Syndrome. New England Journal of Medicine 1996;334:1469-147.

22. Jobe AH. Pulmonary Surfactant Therapy. New England Medical Journal 1993;328:861-868.

23. Bard H, Belanger S, Fouron JC. Comparison of effects of $95 \%$ and $90 \%$ oxygen saturation in RDS. Prenatal and Neonatal Medicine 2001;75 F94-6.

24. Ramanathan R, Rasmussen MR, Gerstmann DR, Finer N, Sekar K. A Randomized, Multicenter Masked Comparison Trial of Poractant Alfa (Curosurf) versus Beractant (Survanta) in the Treatment of Respiratory Distress Syndrome in Preterm Infants. American Journal of Perinatology 2004;21:3

25. Vermont-Oxford Neonatal Network. A multicenter, randomized trial comparing synthetic surfactant with modified bovine surfactant extract in the treatment of neonatal respiratory distress syndrome. Pediatrics 1996;97:1.

26. Ainsworth SB, Beresford MW, Milligan DWA. Pumactant and Poractant alfa for treatment of respiratory distress syndrome in neonates born at 25 to 29 weeks gestation. Lancet 2000;355:1387-139.

27. Ramanathan R, Rasmussen MR. Curosurf and Survanta in the treatment of respiratory distress syndrome in pre term infants. Biol Neonate 2002;81:36. 